\title{
Pengembangan Desa Wisata Kuliner Deret Jurang Sate
}

\author{
${ }^{1}$ Muh Husein Baysha, ${ }^{2}$ Endah Resnandari Puji Astuti, ${ }^{3}$ Noor Akhmad \\ ${ }^{1,2}$ Prodi Teknologi Pendidikan, FIPP, Universitas Pendidikan Mandalika, J1. Pemuda No. \\ 59A, Mataram, Indonesia 83125 \\ ${ }^{3}$ Prodi Pendidikan Olahraga dan Kesehatan, FPOKK, Universitas Pendidikan Mandalika, Jl. \\ Pemuda No. 59A, Mataram, Indonesia 83125
}

Email Korespondensi: baysha234@gmail.com

\begin{tabular}{|c|c|}
\hline Article Info & Abstract \\
\hline $\begin{array}{l}\text { Article History } \\
\text { Received: } 2020-10-13 \\
\text { Revised: } 2020-10-24 \\
\text { Published: } 2020-10-25\end{array}$ & \multirow[b]{2}{*}{$\begin{array}{l}\text { Development of a Culinary Tourism Village, Culinary Jurang Sate. Sepakek } \\
\text { Village has a tourism destination which is not fully managed by the government } \\
\text { and stakeholders. The tourism destination is an irrigation channel that flows } \\
\text { throughout the year, the irrigation channel called Jurang Sate. In } 2019 \text { a min } \\
\text { rafting has been developed to support this Tourism Destination. In } 2020 \text { the } \\
\text { PPDM of University Education of Mandalika groups develop the Culinary of } \\
\text { Jurang Sate to make an attractiveness of tourist to visite this destination, } \\
\text { PPDM of Mandalika groups also inisiates the sustainability of Community } \\
\text { Economical Improvement on the level of Spakek Village by depeloving } \\
\text { Cullinary Tourism of Jurang Sate Village. The culinary line of Jurang Sate } \\
\text { presents a concept by the function is to encourage and sells a variety of } \\
\text { traditional foods and special food of Sepakek village by the community (every } \\
\text { mother and the youth) in that village. In addition, there was also many kinds of } \\
\text { food at Sepakek Village in the form of fresh water, smoked fish which was } \\
\text { processed by using fresh water smoked fish (PETA). The method of } \\
\text { implementing these activities is called community development method which } \\
\text { means the approachment to community development activities in which the } \\
\text { community directed to achieve better social, economic, and cultural conditions } \\
\text { as well as the Participatory Technology Development method, the development } \\
\text { of appropriate technology based on local wisdom and cultural knowledge. This } \\
\text { strategy will develop appropriate technology for smoke fish which is used } \\
\text { barrels. The implementation steps are problem posing, problem analysis, } \\
\text { determination of goals and objectives, action plans, activity implementation } \\
\text { stage and evaluation stage. Through this activity, it is hoped that tourism in the } \\
\text { Sepakek village are able to develop and icrease the economy in this community } \\
\text { The results of this PPDM activity were the arrangement of the Jurang Sate } \\
\text { Tourism destination and the operation of Culinary of Sate Deret }\end{array}$} \\
\hline $\begin{array}{l}\text { Keywords } \\
\text { Tourism Village, } \\
\text { Culinary Series, } \\
\text { Fumigation, } \\
\text { Fresh Fish }\end{array}$ & \\
\hline Ir & Abstrak \\
\hline $\begin{array}{l}\text { Seja } \\
\text { Dite } \\
\text { Dire } \\
\text { Dipu }\end{array}$ & \multirow{2}{*}{$\begin{array}{l}\text { Desa Sepakek memiliki kawasan wisata yang belum dikelola secara maksimal. } \\
\text { Kawasan wisata tersebut merupakan saluran irigasi yang mengalir sepanjang } \\
\text { tahun yaitu saluran irigasi Jurang Sate. Pada tahun } 2019 \text { telah dikembangkan } \\
\text { wahana mini rafting untuk menghidupkan kawasan wisata Jurang Sate. Sebagai } \\
\text { kelanjutan dari usaha menghidupkan kawasan wisata Jurang Sate dan untuk } \\
\text { meningkatkan perekonomian masyarakat Desa Sepakek, pada tahun } 2020 \text { ini } \\
\text { kelompok PPDM Universitas Pendidikan Mandalika mengembangkan Wisata } \\
\text { Kuliner Deret Jurang Sate dengan tujuan menambah daya tarik wisatawan } \\
\text { untuk berkunjung ke Kawasan ini. Kuliner deret Jurang Sate menghadirkan } \\
\text { konsep kuliner yang ditata berderet dengan menarik dan menjual berbagai } \\
\text { makanan tradisional maupun makanan khas Desa Sepakek oleh ibu-ibu dan }\end{array}$} \\
\hline $\begin{array}{l}\text { Kata kunci } \\
\text { Desa Wisata, } \\
\text { Kuliner Dere } \\
\text { Pengasapan, } \\
\text { Ikan Tawar }\end{array}$ & \\
\hline
\end{tabular}


pemuda dari Desa. Selain itu, hadir pula makanan khas Desa Sepakek berupa ikan asap air tawar yang diolah dengan menggunakan TTG pengasapan ikan air tawar (PETA). Metode pelaksanaan kegiatan yaitu dengan metode community development yaitu pendekatan dalam kegiatan pengembangan masyarakat dimana masyarakat diarahkan untuk mencapai kondisi sosial, ekonomi, dan budaya yang lebih baik serta metode Participatory Technology Development yaitu pengembangan teknologi tepat guna yang berbasiskan pada ilmu pengetahuan dan kearifan budaya lokal, dalam hal ini akan dikembangkan teknologi tepat guna alat pengasapan ikan dengan tong bekas. Langkah pelaksanaannya yaitu Problem posing (pemaparan masalah), problem analysis (analisis masalah), penentuan tujuan (aims) dan sasaran (obyectives), actions plans (perencanaan tindakan), tahap pelaksanaan kegiatan dan tahap evaluasi. Melalui kegiatan ini diharapkan pariwisata di Desa Sepakek dapat berkembang sehingga perekonomian dan kesejahtaraan masyarakat dapat meningkat. Hasil kegiatan PPDM ini yaitu tertatanya kawasan Wisata Jurang Sate dan mulai beroperasinya Kuliner Deret Jurang Sate.

Sitasi: Baysha H.M., Astuti P.R.E, \& Akhmad N. (2020) Pengembangan Desa Wisata Kuliner Deret Jurang Sate. Sasambo: Jurnal Abdimas (Journal of Community Service). 2(3), 116-126. DOI: 10.36312/sasambo.v2i3.298

\section{PENDAHULUAN}

Tahun 2019 Tim PPDM Universitas Pendidikan Mandalika telah mengembangkan wahana Mini Rafting di wisata jurang sate Desa Sepakek. Mini rafting ini memanfaatkan aliran irigasi Jurang Sate. Rafting adalah sebuah aktifitas yang memadukan unsur petualangan, adventure, edukasi, olah raga, serta rekreasi dengan mengarungi aliran sungai yang berjeram menggunakan media boat karet dan dayung (Baysha, Astuti, \& Akhmad, 2019).

Program Pengembangan Desa Wisata (PPDM) Wisata Jurang Sate, pada tahun 2020 dikembangkan PETA (Pengasapan Ikan Air Tawar) dan Kuliner Deret Jurang Sate. Pengasapan Ikan Air tawar (PETA) dilakukan dengan manfaatkan hasil perikanan air tawar yang telah dibudidayakan oleh beberapa masyarakat Desa Sepakek yaitu jenis ikan nila dan mujair. Ikan air tawar ini diolah dengan cara diasap sehingga manjadi kuliner khas Jurang Sate. Proses pengasapan menggunakan teknologi tepat guna yang telah dikambangkan sebelumnya yaitu PO Patas atau portabel pengasapan ikan dengan tong bekas (Baysha \& Astuti, 2018). Setelah melalui proses pengasapan, ikan air tawar selanjutnya dikemas dengan hieginis dan menarik sehingga dapat menjadi oleh-oleh kuliner khas wisata Jurang Sate.

Selain itu, dikembangkan Kuliner Deret Jurang Sate yaitu tempat menjual aneka kuliner tradisional Lombok khususnya kuliner tradisional yang dikelola oleh masyarakat Desa Sepakek. Tujuan utama dikembangkannya Kuliner Deret Jurang Sate yaitu untuk menambah daya tarik dan kenyamanan wisatawan Wisata Jurang Sate yang sebelumnya telah disuguhkan dengan wahana Mini Rafting serta untuk meningkatkan perekonomian masyarakat Desa Sepakek pada sektor pariwisata, pertanian, dan perdagangan. Hal ini sejalan dengan pendapat yang menyatakan bahwa kuliner manambah nilai bruto, tenaga kerja juga terserap dari unit usaha yang bergerak pada kuliner dalam kegiatan kepariwisataan (Akbar \& Pangestuti, 2017). Diharapkan melalui pengembangan Kuliner Deret Jurang Sate masyarakat dapat tergugah untuk membuka peluang usaha baru sehingga dapat berdampak positif bagi kegiatan ekonomi masyarakat Desa Sepakek.

Sebagai usaha lanjutan untuk memajukan Wisata Jurang Sate, kelompok PPDM Universitas Pendidikan Mandalika bermitra dengan Karang Taruna, Bumdes, dan Pokdarwis. Mitra I kegiatan PPDM ini adalah Karang taruna Desa Sepakek yang bernama Duta Taruna. Bentuk kemitraan yang dilakukan dengan karang taruna Duta Taruna yaitu bersama-sama membangun ekonomi produktif masyarakat Desa Sepakek melalui pengembangan wahana mini rafting Jurang Sate yang mana telah terlaksana pada tahun 2019. Dengan adanya wahana 
Mini Rafting Jurang Sate dan penataan lingkungan Wisata Jurang Sate terbukti telah dapat menambah daya tarik masyarakat untuk melakukan kunjungan ke Wisata Jurang Sate.

Mitra II yaitu Bumdes (Badan Usaha Milik Desa) Sepakek. Bumdes Desa Sepakek bernama Sahara Jaya berperan menggerakkan masyarakat dalam memperkuat perekonomian desa dengan memanfaatkan berbagai potensi yang ada dan dimiliki oleh Desa Sepakek. Berdasarkan peran tersebut, kelompok PPDM Universitas Pendidikan Mandalika bersama Bumdes Sepakek akan mengembangkan PETA (Pengasapan Ikan Air Tawar) dan usaha Kuliner Deret Jurang Sate. Kelompok PPDM Universitas Pendidikan Mandalika bersama Bumdes mengambangkan usaha pengolahan ikan air tawar dengan pengasapan sehingga hasil olahan ikan asap dapat dijadikan produk khas Wisata Jurang Sate. Selain itu, akan dikembangkan pula Kuliner Deret Jurang Sate dimana akan ditata tempat menjual berbagai makanan tradisional khas Lombok atau kuliner secara berderet di kawasan Wisata Jurang Sate. Dalam mempersiapkan berbagai makanan atau kuliner khas Lombok, Tim PPDM Universitas Pendidikan Mandalika akan melakukan pendataan mengenai berbagai makanan khas Lombok sesuai dengan potensi Desa Sepakek dan melakukan pelatihan mengenai kuliner khas Lombok serta cara pengemasan yang hieginis dan menarik. Kegiatan ini ditujukan terutama bagi ibu-ibu dan pemuda-pemudi desa Sepakek sehingga baik ibu-ibu maupun pemuda-pemudi Desa Sepakek dapat turut serta dalam mambangun perekonomian Desa Sepakek.

Mitra III kegiatan ini yaitu Pokdarwis (Kelompok Sadar Wisata) Desa Sepakek yang bernama Kenak Jarin. Pokdarwis Kenak Jarin berperan dalam melakukan aktivitas sosial yang berupaya untuk meningkatkan pemahaman kepariwisataan kepada masyarakat, meningkatkan peran dan partisipasi masyarakat dalam pembangunan kepariwisataan, meningkatkan nilai manfaat kepariwisataan bagi masyarakat, serta mensukseskan pembangunan kepariwisataan. Berdasarkan peran tersebut, kelompok PPDM Universitas Pendidikan Mandalika bersama Pokdarwis Kenak Jarin akan bersama-sama merangkul masyarakat untuk turut berperan dan membangun Desa Sepakek menjadi kawasan wisata yang memiliki daya tarik bagi wisatawan baik wisatawan domestik maupun mancanegara. Selain itu, Tim PPDM Universitas Pendidikan Mandalika bersama Pokdarwis akan menggerakkan masyarakat dalam melakukan dan menyelenggarakan berbagai kegiatan sebagai bentuk promosi Wisata Jurang Sate baik melalui Festival Wisata Jurang Sate maupun promosi melalui berbagai media seperti media cetak, social media, dan media digital.

Berdasarkan uraian di atas maka tujuan dari kegiatan Program Pengembangan Desa Wisata (PPDM) adalah menambah daya tarik wisatawan untuk berkunjung ke Kawasan Jurang Sate, selain itu kuliner deret Jurang Sate menghadirkan konsep kuliner yang ditata berderet dengan menarik dan menjual berbagai makanan tradisional maupun makanan khas Desa Sepakek oleh ibu-ibu dan pemuda dari Desa.

\section{METODE}

Metode yang digunakan dalam program kegiatan PPDM melalui Kuliner Deret Jurang Sate adalah metode community development yaitu pendekatan dalam kegiatan pengembangan masyarakat dimana masyarakat diarahkan untuk mencapai kondisi sosial, ekonomi, dan budaya yang lebih baik, sehingga diharapkan masyarakat dapat lebih mandiri dengan kualitas kehidupan dan kesejahteraan yang lebih baik pula. Karakteristik utama metode community development adalah pengembangan pariwisata berbasis masyarakat (community based tourism), berbasis sumber daya setempat (lokal resources based), dan berkelanjutan (sustainable tourism).

Langkah-langkah pelaksanaan program kegiatan PPDM Kuliner Deret Jurang Sate, sebagai berikut. 
1. Problem posing (pemaparan masalah)

Kegiatan ini dilakukan pengelompokan dan penentuan masalah yang dihadapi oleh masyarakat kelompok mitra. Dalam kegiatan ini permasalahan yang dihadapi oleh masyarakat Desa Sepakek yaitu mengenai bagaimana mengembangkan perekonomian masyarakat di sektor pariwisata dengan mengembangkan kawasan wisata irigasi Jurang Sate.

2. Problem analysis (analisis masalah)

Tahap ini kelompok PPDM Universitas Pendidikan Mandalika melakukan pengumpulan berbagai informasi dari berbagai sumber guna memperoleh alternatif solusi dari permasalahan yang dihadapi oleh masyarakat mitra.

3. Penentuan tujuan (goal setting) dan sasaran (obyectives)

Tahap ini ditentukan tujuan kegiatan yang jelas baik tujuan jangka panjang maupun tujuan jangka pendek. Selain itu ditentukan pula sasaran masyarakat yang akan memperoleh perlakuan kegiatan.

4. Actions plans (perencanaan tindakan)

Tahap ini kelompok PPDM menentukan berbagai aksi atau tindakan atau perlakuan yang akan diberikan untuk mencapai tujuan. Perencanaan tindakan yang dilakukan untuk meningkatkan perekonomian masyarakat Desa Sepakek pada sektor perekonomian dan pariwisata yaitu:

a. Pembentukan kelompok Kuliner Deret Jurang Sate

b. Pelatihan pengembangan usaha kuliner lokal di Wisata Jurang Sate

c. Pemetaan kuliner khas lokal

d. Pemetaan jajanan khas lokal

e. Pengadaan dan penataan kuliner Deret Wisata Jurang Sate

f. Pelatihan mengenai PETA (Pengasapan Ikan Air Tawar) sebagai oleh-oleh khas Wisata Jurang Sate

g. Persiapan peralatan dan pelaksanaan pembuatan PETA

h. Pelatihan produksi kuliner bersih, enak, dan sehat

i. Pelatihan pengemasan Ikan asap air tawar bersih, enak, dan sehat

5. Tahap pelaksanaan kegiatan

Kelompok PPDM bersama dengan mitra melaksanakan semua kegiatan yang telah direncanakan.

6. Tahap evaluasi

Kelompok PPDM akan melakukan evaluasi terhadap proses kegiatan yang berlangsung secara berkelanjutan agar dapat diketahui kekurangan serta kelebihan program kegiatan dan dapat dilakukan perbaikan terhadap kekuranga-kekurangan yang ada.

\section{HASIL DAN PEMBAHASAN}

Pelaksanaan pengabdian kepada masyarakat Program Pengembangan Desa Mitra (PPDM) Pengembangan Wisata Jurang Sate tahun kedua yaitu mengembangkan wisata Kuliner Deret Jurang Sate. Beberapa tahapan kegiatan dalam pelaksanaan pengembangan kuliner Deret Jurang Sate adalah sebagai berikut:

1. Mempersiapkan Peralatan Pengasapan Ikan Air Tawar (PETA) dan Lapak Deret

Peralatan pengasapan ikan air tawar merupakan teknologi tepat guna yang memanfaatkan tong atau drum sebagai bahan pokok peralatan yang dirancang khusus sehingga menjadi peralatan pengasapan yang dapat dipindah dengan mudah karena memiliki roda. Berikut adalah bahan yang diperlukan untuk membuat teknologi tepat guna pengasapan ikan air tawar (PETA): 1) drum bekas 2 buah; 2) pipa corong 1 buah ukuran tinggi $0,5 \mathrm{~m}$ dengan diameter $8 \mathrm{~cm}$; 3) pipa penghubung antar drum/tong 2 buah dengan ukuran $15 \mathrm{~cm}$ diameter $8 \mathrm{~cm}$; 4) rak besi 2 buah dengan ukuran; 5) thermometer pengatur suhu; 6) penutup alat Po Patas; 7) besi penyangga; 8) roda 4 buah. 
Selanjutnya, perakitan alat teknologi tepat guna pengasapan ikan air tawar (PETA) yaitu dengan menggabungkan 2 drum/tong berdasarkan gambar berikut:
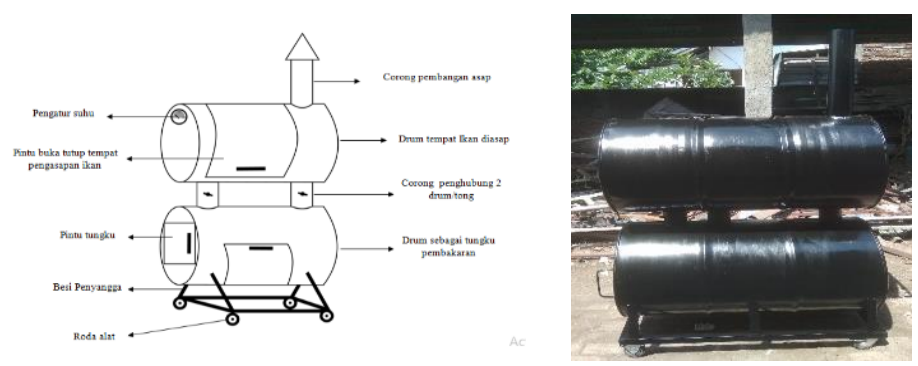

Gambar 1. Teknologi Tepat Guna Pengasapan Ikan Air Tawar (PETA)

Teknologi tepat guna pengasapan ikan air tawar (PETA) terdiri dari dua bagian ruang dimana ruang bagian bawah merupakan drum/tong untuk tempat pengapian atau pembakaran kayu. Tong/drum bagian atas merupakan ruang tempat ikan air tawar diasapi. Pada bagian atas ini terdapat rak-rak bersusun dua untuk meletakkan ikan dan juga tempat gantungan untuk menggantung ikan. Kedua bagian tong/drum ini dihubungkan dengan tiga pipa dari alumuniaum agar asap dari ruang pengapian dapat masuk ke ruang tempat ikan. Teknologi tepat guna ini juga dilengkapi dengan penunjuk suhu agar dapat diketahui berapa derajat suhu selama proses pengasapan. Teknologi tepat guna pengasapan ikan air tawar (PETA) ini selanjutnya digunakan untuk melakukan pengasapan terhadap ikan tawar yang dihasilkan oleh masyarakat Desa Sepakek. Berikut adalah gambar bagian alat pengasapan ikan air tawar (PETA).
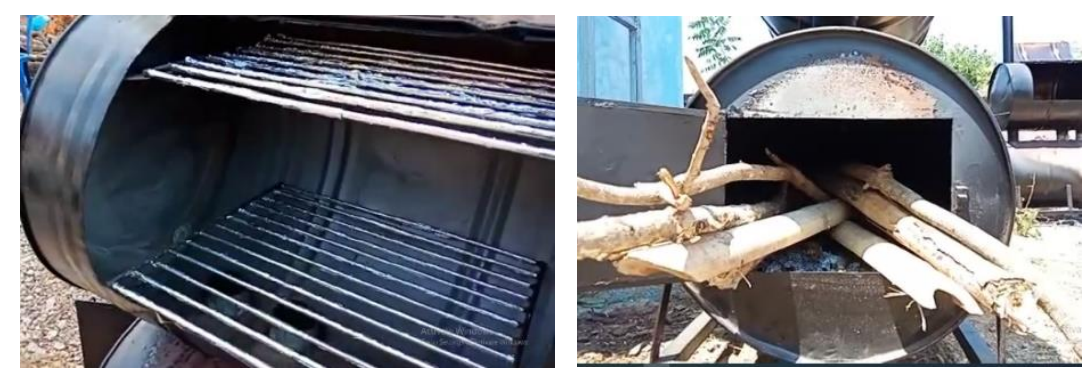

Gambar 2. Bagian Atas (Rak Ikan) dan Bagian Bawah (Pengapian) Alat Pengasapan Ikan

Lapak deret Jurang Sate dibuat menyerupai container yang dirancang sehingga dapat menjadi tempat jualan yang nyaman dan menarik. Lapak deret yang dibuat yaitu sebanyak 8 container yang ditempatkan berderet di kawasan Wisata Jurang Sate. Bahan utama yang diperlukan dalam pembuatan container lapak deret jurang Sate adalah sebagai berikut: (1) spandek; (2) Besi 3 x $3 \mathrm{~cm}, 2 \mathrm{~mm}$; (3) Besi biasa SNI ukuran per besi $8 \mathrm{~m}$; (3) tripplek $6 \mathrm{~mm}$ ukuran 240 x $90 \mathrm{~cm}$; (4) engsel pintu dan jendela; (5) cat dan teener. Selanjutnya bahanbahan tersebut melalui proses pemotongan, mengecatan, pembuatan rangka, pemasangan spandek pada rangka, pembuatan meja triplek, pembuatan pintu dan jendela, serta finishing.
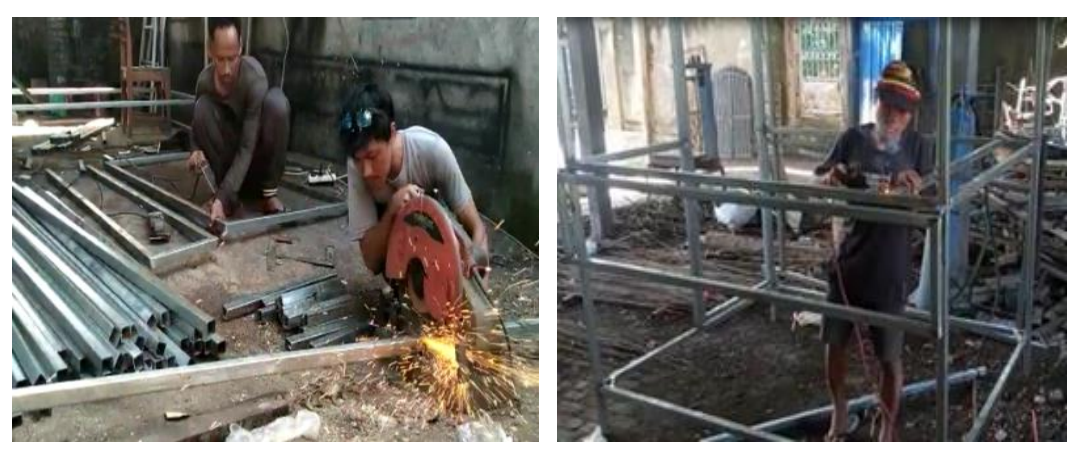

Gambar 3. Proses Pemotongan Besi dan pembuatan rangka container 
2. Sosialisasi Kuliner Deret Jurang Sate pada Masyarakat Desa Sepakek

Kegiatan sosialisasi kuliner Deret Jurang Sate dan kegiatan pengasapan ikan air tawar (PETA) dilaksanakan pada tanggal 5 Juli 2020 bertempat di Kantor Desa Sepakek. Kegiatan Sosialisasi ini dihadiri oleh Kepala Desa dan staf Desa Sepakek, Kepala Dusun yang berada di wilayah Desa Sepakek, pemuka adat, anggota karang taruna, anggota pokdarwis, anggota bumdes, serta perwakilan masyarakat terutama yang bertempat di lingkungan sekitar Wisata Jurang Sate. Kegiatan sosoalisasi ini bertujuan untuk memberikan informasi awal mengenai kuliner deret Jurang Sate serta kegiatan pengasapan ikan tawar (PETA) di lingkungan Desa Sepakek. Kegiatan ini juga mengajak seluruh warga Desa untuk turut berpartisipasi dalam membangun wisata di Desa Sepakek agar dapat meningkatkan perekonomian masyarakat Desa Sepakek. Masyarakat juga dihimbau untuk memiliki komitmen dalam menjaga citra dan nama baik Desa Sepakek sebagai Desa Wisata serta menjaga seluruh fasilitas umum milik Desa Sepakek khususnya yang berada di Kawasan Wisata Desa Sepakek.

3. Pelatihan dan Pendampingan Pengenalan Peralatan PETA sebagai Produk Khas Jurang Sate

Pelatihan pengenalan peralatan pengasapan ikan air tawar (PETA) dilaksanakan pada tanggal 8 Juli 2020. Dalam kegiatan ini, Tim PPDM UNDIKMA memperkenalkan teknologi tepat guna pengasapan ikan air tawar (PETA) dan cara kerja alat pengasapan ikan ini. Pelatihan ini diikuti oleh 30 peserta yang berasal dari masyarakat Desa Sepakek, terdiri dari anggota karang taruna Duta Taruna, anggota Bumdes Sahara Jaya, dan perwakilan masyarakat Desa Sepakek.

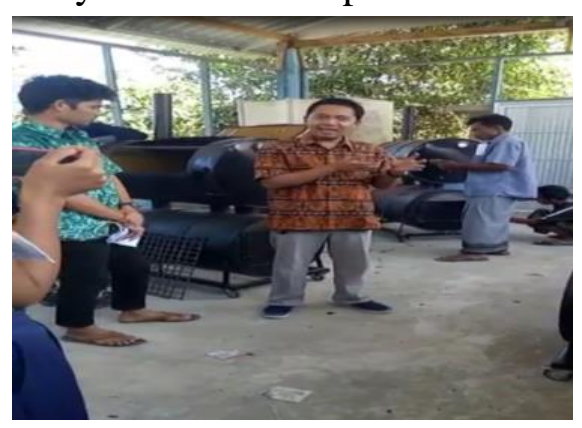

Gambar 4. Pelatihan Pengenalan Peralatan Pengasapan Ikan Air Tawar (PETA)

Berdasarkan hasil kegiatan pelatihan ini diperoleh peningkatan pada aspek pengetahuan mitra atau masyarakat Desa Sepakek sebagai berikut:

Tabel 1. Peningkatan Aspek Pengetahuan Mitra dalam Pelatihan Pengenalan Peralatan Pengasapan Ikan Air Tawar (PETA)

\begin{tabular}{ccc}
\hline \multirow{2}{*}{ Uraian } & \multicolumn{2}{c}{ Tingkat Pengetahuan } \\
\cline { 2 - 3 } & Sebelum Pelatihan & Sesudah Pelatihan \\
\hline
\end{tabular}

Program Pelatihan 1. Sebanyak 50\% peserta 1. Sebanyak $100 \%$ peserta

Pengenalan mengetahui cara pengawetan peralatan ikan air tawar dengan pengasapan ikan air pengasapan

tawar

2. Sebanyak $20 \%$ peserta belum mengetahui cara pengasapan ikan air tawar menggunakan mesin/alat dengan memanfaatkan tong/drum mengetahui cara pengawetan ikan melalui pengasapan

2. Sebanyak $90 \%$ peserta mengetahui cara pengasapan ikanaiar tawar menggunakan mesin/alat drum/tong.

3. Semua peserta belum 3. Sebanyak $80 \%$ peserta telah mengetahui bagian-bagian mengetahui bagian-bagian peralatan pengasapan ikan peralatan pengasapan ikan air 
4. Semua peserta belum 4. Sebanyak $90 \%$ peserta telah mengetaui teknik-teknik dan prosedur penggunaan peralatan pengasapan ikan mengetahui penggunaan prosedur air tawar pengasapan ikan air tawar

Berdasarkan data di atas, rata-rata pengetahuan masyarakat Desa Sepakek dalam pengawetan ikan dan pengetahuan mengenai alat/mesin pengasapan ikan air tawar (PETA) sebelum pelatihan yaitu sebesar $17,5 \%$ meningkat menjadi $90 \%$ setelah adanya pelatihan pengenalan peralatan pengasapan ikan air tawar (PETA).

Kegiatan pelatihan dan pendampingan Pengasapan ikan air tawar (PETA) kepada masyarakat Desa Sepakek dilaksanakan pada tanggal 9-10 Juli 2020. Dalam kegiatan ini mitra atau peserta pelatihan diajak untuk mempraktekkan cara melakukan pengasapan ikan air tawar mulai dari proses pemilihan ikan air tawar yang baik, membersihkan ikan, memberi bumbu, perendaman bumbu, penirisan ikan, pengapian hingga pengasapan dengan menggunakan alat pengasapan ikan air tawar (PETA).
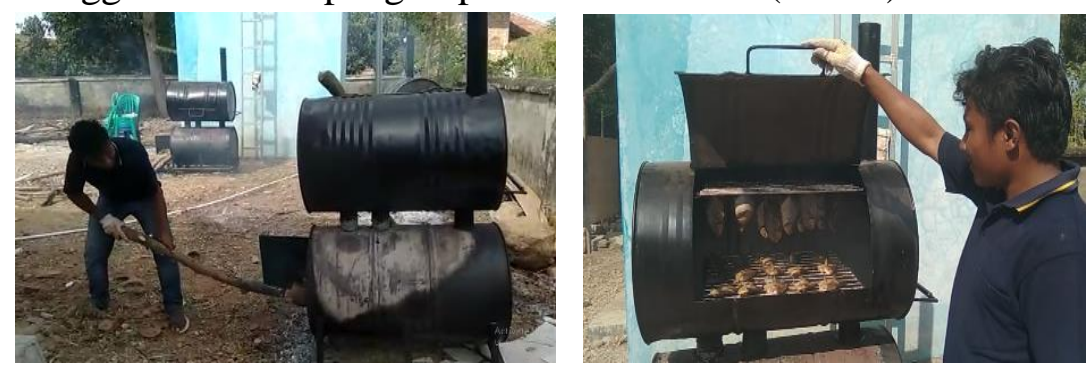

Gambar 5. Proses Pengasapan Ikan Air Tawar

Hasil pelatihan dan pendampingan pengasapan ikan air tawar (PETA) pada masyarakat Desa Sekapek menunjukkan adanya peningkatan dalam aspek keterampilan yaitu:

Tabel 2. Peningkatan Keterampilan dan Ekonomi Mitra dalam Pelatihan dan Pendampingan Pengasapan Ikan Air Tawar (PETA)

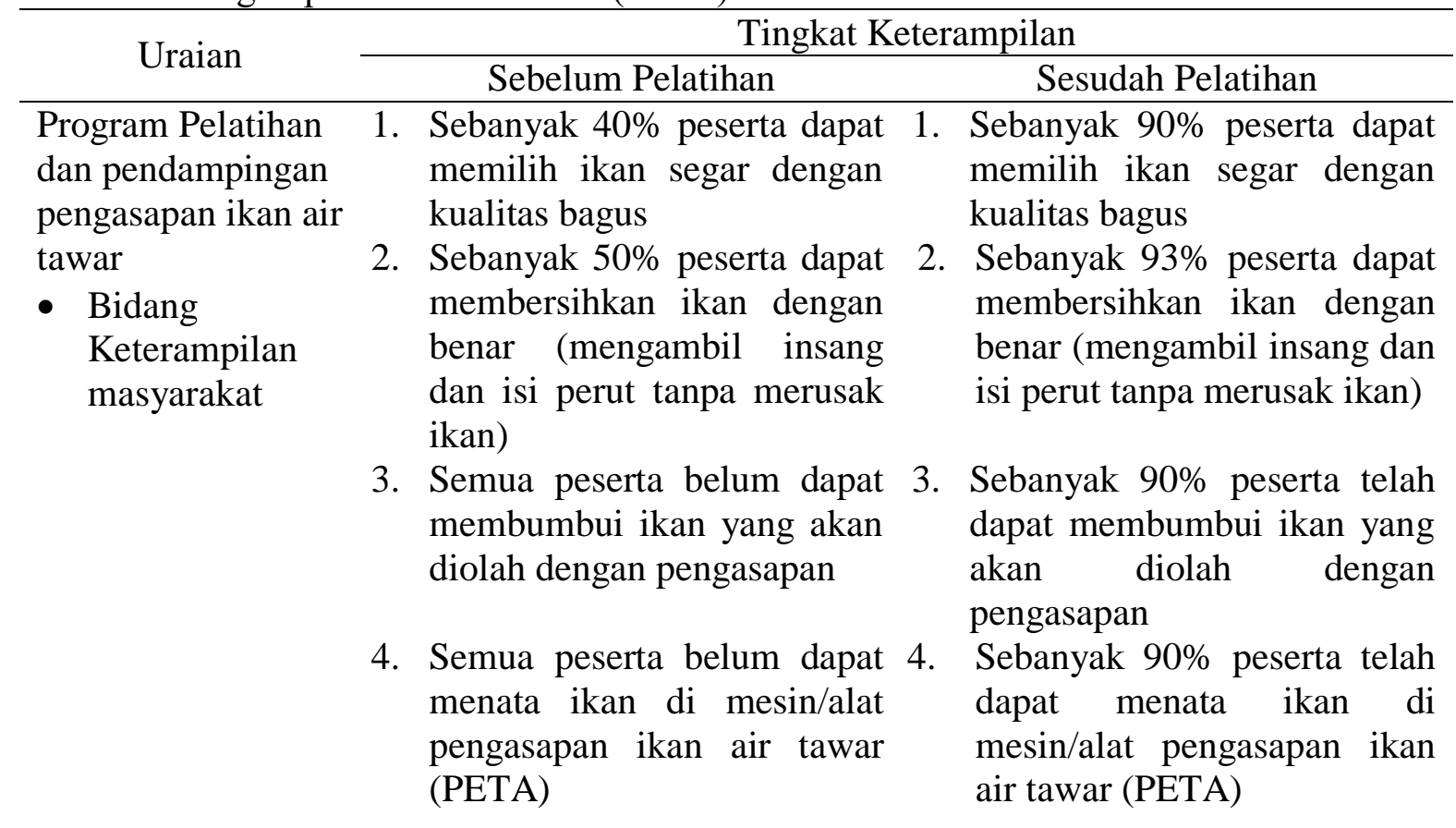


- Bidang Ekonomi masyarakat
5. Sebanyak $30 \%$ peserta dapat melakukan proses pengapian pada mesin pengasapan ikan air tawar (PETA)

6. Belum ada peserta yang dapat mengoperasikan mesin pengasapan ikan air tawar (PETA) dengan benar

7. Belum ada produk khas Wisata Jurang sate yang siap dipasakan

8. Ikan air tawar mentah dijual dengan harga Rp 15.000,per kg
5. Sebanyak $80 \%$ peserta dapat melakukan proses pengapian pada mesin pengasapan ikan air tawar (PETA

6. Sebanyak $80 \%$ peserta dapat mengoperasikan mesin pengasapan ikan air tawar (PETA)

7. Sebanyak $90 \%$ produk ikan asap air tawar sebagai produk khas Wisata jurang Sate siap untuk dipasarkan.

8. Ikan asap dijual dengan harga Rp 35.000,- per kg

Berdasarkan data di atas, rata-rata keterampilan masyarakat Desa Sepakek/mitra dalam mengolah ikan asap dan mengoperasikan alat/mesin pengasapan ikan air tawar (PETA) sebelum pelatihan yaitu sebesar $20 \%$ meningkat menjadi $87 \%$ setelah adanya pelatihan dan pendampingan pengasapan ikan air tawar (PETA). Sementara untuk bidang ekonomi, terjadi peningkatan pada penjualan produk ikan asap yang awalnya ikan mentah dijual dengan harga Rp 15.000,- per kg menjadi Rp 35.000,-/kg setelah diolah menjadi ikan asap dan dikemas dengan baik.

Kegiatan pelatihan makanan bersih, enak dan sehat dilaksanakan pada tanggal 11 Juli 2020. Kegiatan ini diikuti oleh 30 orang peserta masyarakat Desa Sepakek. Materi yang diberikan dalam pelatihan ini yaitu mengenai cara pengemasan makanan yang enak, bersih dan sehat. Masyarakat Desa Sepakek yang nantinya menjadi tuan rumah di Wisata Jurang Sate perlu selalu mengutamakan kebersihan dalam menjual makanan. Pengemasan yang baik dan menarik perlu diperhatikan juga untuk menjaga makanan tetap aman dikonsumsi oleh pengunjung dan menambah daya jual makanan. Setelah materi diberikan, peserta pelatihan juga diberi praktek cara pengemasan ikan asap yang telah dibuat pada pelatihan sebelumnya. Pengemasan ikan tawar asap dilakukan dengan menggunakan mesin vacuum sealer agar ikan asap dapat tetap sehat dan bersih untuk dipasarkan kepada pengunjung wisata Jurang Sate serta dapat bertahan lebih lama.

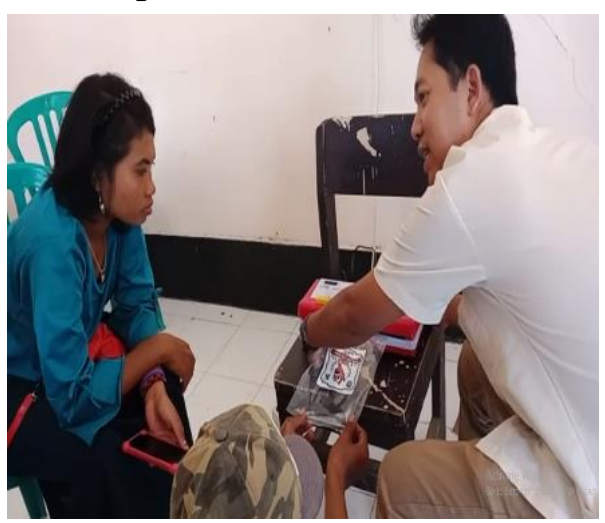

Gambar 6. Pelatihan Pengemasan Ikan Asap dengan Vacum Sealer

Berdasarkan hasil pelatihan tersebut diperoleh peningkatan keadaan masyarakat dalam aspek pengetahuan dan keterampilan. Berikut adalah uraian beberapa aspek tersebut: 
Tabel 3. Peningkatan Pengetahuan Mitra dalam Pelatihan Pengemasan Makanan Bersih, Enak dan Sehat

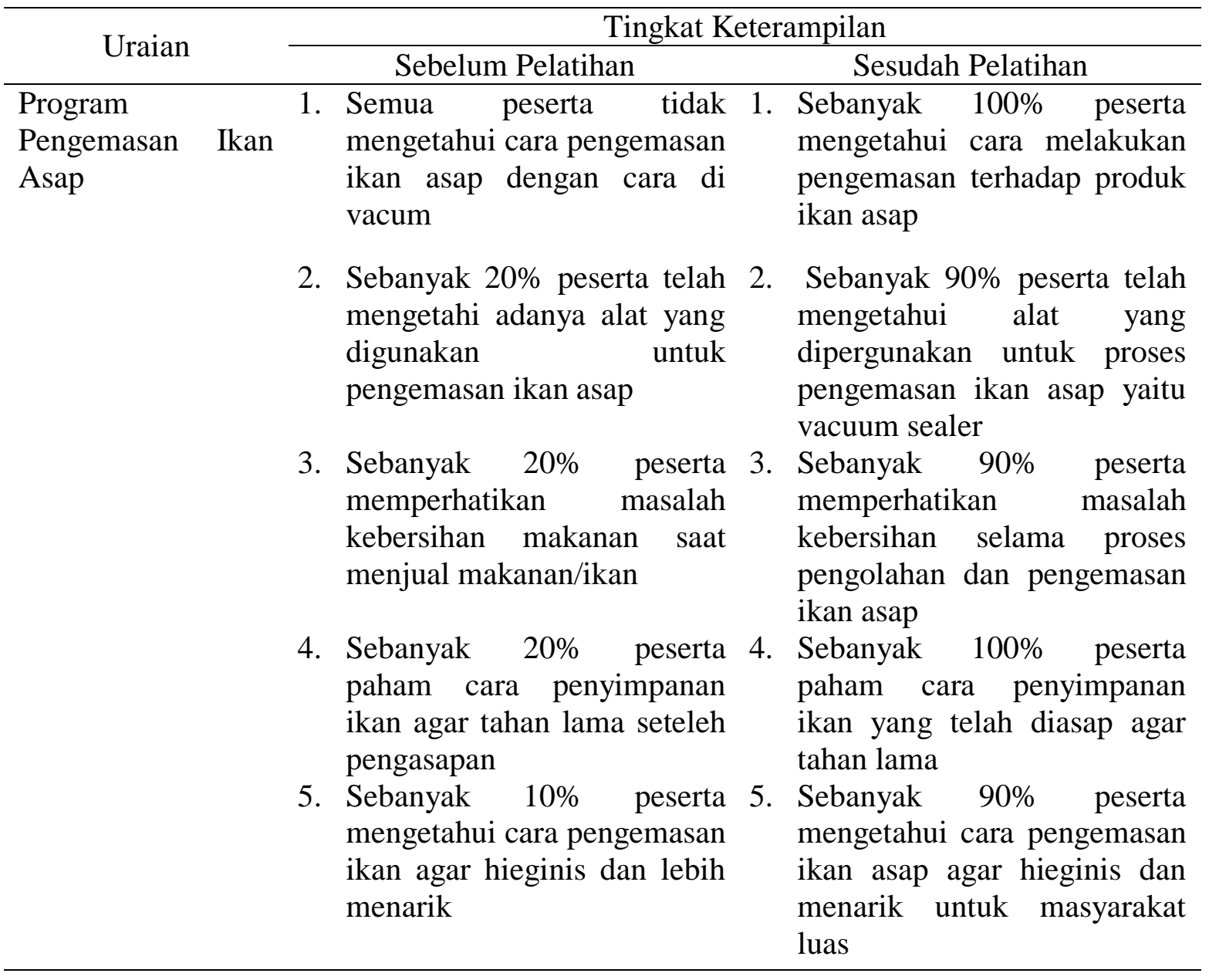

Tabel 4. Peningkatan Keterampilan Mitra dalam Pelatihan Pengemasan Makanan Bersih, enak dan Sehat

\begin{tabular}{|c|c|c|c|}
\hline \multirow{2}{*}{\multicolumn{2}{|c|}{ Uraian }} & \multicolumn{2}{|c|}{ Tingkat Keterampilan } \\
\hline & & Sebelum Pelatihan & Sesudah Pelatihan \\
\hline \multirow{2}{*}{$\begin{array}{l}\text { Program } \\
\text { Pengemasan } \\
\text { Asap }\end{array}$} & Ikan & $\begin{array}{l}\text { 1. Semua peserta belum dapat } \\
\text { memberi label pada kemasan }\end{array}$ & $\begin{array}{l}\text { 1. Sebanyak } 93 \% \text { peserta dapat } \\
\text { memberi label pada kemasan }\end{array}$ \\
\hline & & $\begin{array}{l}\text { 2. Semua peserta belum dapat } \\
\text { mengoprasikan mesin } \\
\text { vacuum sealer dengan benar }\end{array}$ & $\begin{array}{l}\text { 2. Sebanyak } 80 \% \text { peserta dapat } \\
\text { mengoprasikan mesin } \\
\text { vacuum sealer dengan benar }\end{array}$ \\
\hline
\end{tabular}

Berdasarkan data di atas, pengetahuan mitra dalam pengemasan makanan bersih, enak dan sehat sebelum pelatihan yaitu dengan rata-rata14\% meningkat menjadi $94 \%$ setelah adanya pelatihan. Begitu juga dengan keterampilan mitra, sebelum pelatihan semua mitra belum memiliki keterampilan dalam meberi label pada kemasan dan belum dapat mengoperasikan vacuum sealer dengan benar. Setelah pelatihan keterampilan mitra meningkat dengan rata-rata $86,5 \%$.

\section{Pelatihan Pengembangan Usaha Kuliner Lokal Jurang Sate}

Kegiatan pelatihan pengembangan Usaha Kuliner Lokal Jurang Sate dilaksanakan pada tanggal 7 September 2020. Kegiatan pelatihan ini diawali dengan pembentukan kelompok kuliner deret Jurang Sate. Anggota kelompok kuliner deret Jurang Sate merupakan 
masyarakat Desa sepakek yang berkomitmen untuk terus mengembangkan usahanya di Wisata Jurang Sate serta mantaati peraturan/ketentuan dari Desa Sepakek. Kelompok kuliner Deret Jurang Sate dapat menjajakan berbagai makanan atau jajanan khas dari Daerah Sepakek agar dapat dinikmati oleh pengunjung yang dating ke Wisata jurang Sate.

Dalam pelatihan ini mitra diberi materi mengenai strategi pengembangan usaha kuliner local termasuk di dalamnya yaitu strategi pemasaran makanan khas wisata Jurang Sate yaitu ikan asap yang dapat dijadikan oleh-oleh khas dari Wisata jurang Sate.

Kegiatan pelatihan dan penataan kuliner deret Jurang Sate dilaksanakan pada tanggal 11-13 Agustus 2020. Dalam kegiatan ini, masyarakat akan diajak untuk bersama-sama melakukan penataan Kuliner Deret Jurang Sate. Kuliner Deret Jurang Sate merupakan Lapak Kuliner menyerupai container yang ditata berderet pada tempat yang telah di tentukan pada kawasan Wisata jurang Sate. Lapak container ini berukuran Panjang $200 \mathrm{~cm}$ x Lebar $150 \mathrm{~cm}$ $\mathrm{x}$ Tinggi $180 \mathrm{~cm}$. Lapak ini di cat dengan warna yang beragam/berbeda-beda dengan maksud agat lebih menarik. Lapak container Wisata Kuliner Deret Jurang Sate berjumlah 8 lapak. Selain lapak container, akan diberikan pula payung hias beserta tempat duduk pada setiap lapak yang ada agar pengunjung dapat lebih nyaman berbelanja atau menghabiskan waktu bersantai di Wisata Jurang Sate. Secara resmi Kuliner Deret Jurang Sate beroperasi pada bulan Oktober 2020.

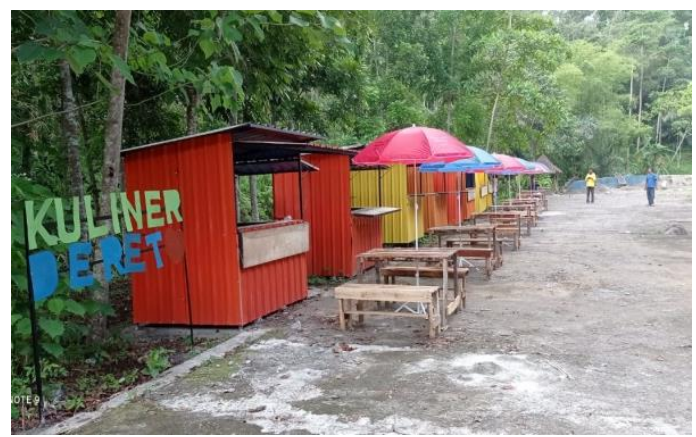

Gambar 8. Lapak Container untuk Wisata Kuliner Deret Jurang Sate

\section{KESIMPULAN}

Pelaksanaan PPDM Pengembangan wisata Jurang Sate, Tim PPDM Universitas Pendidikan Mandalika bermitra dengan karang taruna Duta Taruna, Pokdasrwis Kenak Jarin, dan Bumdes Sahara Jaya di Desa Sepakek, Kecamatan Pringgarata, Lombok Tengah. Pelaksanaan pengembangan wisata Jurang Sate diawali dengan penataan kawasan Wisata Jurang sate dan pembukaan wahana mini rafting Jurang Sate yang telah dilaksanakan pada tahun 2019. Pada tahun kedua dibangun dan beroperasinya kuliner deret Jurang Sate serta adanya makanan khas Wisata Jurang Sate berupa ikan tawar asap. Ikan tawar ini diolah menjadi makanan khas Wisata Jurang Sate dengan memanfaatkan teknologi tepat guna pengasapan ikan air tawar (PETA). Pelaksanaan seluruh kegiatan ini melibatkan mitra dan masyarakat Desa Sepakek untuk bersama-sama bergotong royong menata Kuliner Deret Jurang Sate dan turut serta dalam kegiatan pelatihan dan pendampingan yang diselenggarakan Tim PPDM UNDIKMA. Saat ini persiapan pembukaan kuliner Deret Jurang Sate telah sampai pada persiapan seluruh peralatan dan adanya makanan khas wisata Jurang Sate

\section{SARAN}

Saran setelah terlaksana program kegiatan ini hendaknya pemerintah desa sepakek membuat kebijakan dan regulasi terkait tata kelola wisata kuliner deret jurang sate. Sinergitas pengelolaan wisata oleh pemerintah desa dan stakeholder masyarakat mempercepat terwujudnya desa sepakek menjadi desa wisata dimana masyarakat merasakan dampak positif wisata terkait peningkatan perekonomian. Rencana kegiatan pada tahun ketiga yaitu Festival 
Wisata Jurang Sate. Kegiatan ini dilakukan sebagai sarana promosi dan daya tarik bagi wisatawan, baik wisatawan dalam negeri maupun luar negeri, mengingat saat ini Pulau Lombok adalah salah satu destinasi wisata yang digemari oleh wisatawan. Dalam Festival Wisata Jurang Sate akan diadakan berbagai kegiatan yang dapat menarik banyak wisatawan seperti kompetisi mini rafting sebagai wisata unggulan di kawasan wisata Jurang Sate, kompetisi 'selfi' Jurang Sate, pameran foto, kompetisi Jaje Sasak, penampilan Gendang Belek Sasak, workshop pengasapan ikan air tawar (PETA) sebagai produk kuliner khas Jurang Sate dan kirab budaya sasak. Diharapkan dengan diadakannya festival ini wisatawan baik dalam maupun luar negeri akan tertarik berkunjung ke Wisata Jurang Sate. Kegiatan festival dapat dijadikan selain sebagai ajang promosi juga sebagai sarana rekreasi, edukasi budaya, organisasi, serta motivasi bagi pemuda di Desa Sepakek untuk lebih memajukan pariwisata yang mereka miliki. Selain itu, masyarakat juga akan lebih terbuka dalam menerima wisatawan dan dapat lebih kreatif dalam menemukan peluang usaha (Baysha, dkk., 2019) baru dari sektor pariwisata Jurang Sate. Hal ini sejalan dengan pernyataan yang menyatakan bahwa dengan adanya event/kegiatan seperti pameran ataupun festival dapat memberikan fungsi sebagai sarana edukasi, rekreasi, prestasi, motivasi, berorganisasi serta sebagai sarana promosi (Baysha \& Astuti, 2017).

\section{UCAPAN TERIMA KASIH}

Program PDDM dapat berjalan dan terselesaikan dengan baik karena dukungan dari 1) Kementerian Riset, Teknologi, dan Inovasi (RISTEKBRIN), 2) LPPM Universitas Pendidikan Mandalika, 3) Rektor, Dekan Fakultas Ilmu Pendidikan dan Psikologi, dan Ketua Prodi Teknologi Pendidikan, 4) Kepala Desa Sepakek, beserta segenap jajarannya, dan warga masyarakat, 5) Ketua Karang Taruna Duta Taruna, Ketua Pokdarwis Kenak Jarin, dan Ketua Bumdes Sahara Jaya, 6) Mahasiswa KKN periode 2020 Universitas Pendidikan Mandalika

\section{DAFTAR PUSTAKA}

Akbar, A. T., \& Pangestuti, E. (2017). Peran Kuliner dalam Meningkatkan Citra Destinasi Pariwisata Taman Nasional Bromo Tengger Semeru. Jurnal Administrasi Bisnis (JAB), 153-159.

Baysha, M. H., \& Puji Astuti, E. R. (2017). Pameran Fotografi Berbasis Project Based Learning. Prosiding Seminar Nasional Pendidikan FKIP UNTIRTA (hal. 151-158). Serang Banten: UNTIRTA.

Baysha, M. H., \& Puji Astuti, E. R. (2018). Peningkatan Perekonomian Masyarakat Pesisir Pulau Lombok melalui "Po Patas". Jurnal Ilmiah Mandala Education (JIME), 25-32.

Baysha, M. H., Puji Astuti, E. R., \& Akhmad, E. (2019). Pengembangan Desa Wisata Mini Rafting Jurang Sate. SASAMBO: Jurnal Abdimas (Journal of COmmunity Service), 2435 . 